\title{
Supporting Urban Air Mobility with Citizen Participatory Noise Sensing: A Concept
}

\author{
Hinnerk Eißfeldt \\ Department of Aviation and Space Psychology \\ DLR German Aerospace Center, Hamburg, Germany, hinnerk.eissfeldt@dlr.de
}

\begin{abstract}
Looking ahead, in about 20 years, there is likely to be urban air mobility in larger cities across the globe. If economic predictions come true, thousands of air taxi flights will take place daily in capital cities - not only in megacities. Noise generated by urban flight mobility has been identified as a critical factor in this development. A concept is proposed to help raise the tolerance level for urban air noise among communities as well as of individual residents by means of transparency. This concept views residents as stakeholders in urban air mobility and widens the call for continuous noise measurements of vertical take-off and landing operations on individual site basis [1] by residents voluntary on-site data collection enabled by smartphone-based participatory noise sensing (PNS). In the presentation of this concept, this discussion paper describes important aspects of social acceptance of urban air mobility.
\end{abstract}

\section{CCS CONCEPTS}

- Applied computing Aerospace • Networks Public Internet - Human-centered computing Collaborative content creation - Hardware Sound-based input / output

\section{KEYWORDS}

Urban air mobility; environmental noise; air taxi; smartphone; community map; participatory noise sensing; noise annoyance

\section{ACM Reference format:}

Hinnerk Eißfeldt. 2019. Supporting Urban Air Mobility with Citizen Participatory Noise Sensing: A Concept. In Proceedings of WWW'19: The Web Conference (WWW'19), May 13, 2019, San Francisco, USA. ACM, New York, NY, USA, 3 pages. https://doi.org/10.1145/3308560.3317059

\section{Introduction}

Looking ahead, in about 20 years, there is likely to be urban air mobility (UAM) in larger cities across the globe. Air taxis will serve individual on-demand transportation needs. They will also connect important transportation nodes, for instance the city

This paper is published under the Creative Commons Attribution 4.0 International (CC-BY 4.0) license. Authors reserve their rights to disseminate the work on their personal and corporate Web sites with the appropriate attribution.

WWW'19, May 13, 2019, San Francisco, USA

(c) 2019 IW3C2 (International World Wide Web Conference Committee), published under Creative Commons CC-BY 4.0 License.

ACM ISBN 978-1-4503-6675-5/19/05.

https://doi.org/10.1145/3308560.3317059 center with the airport, and will provide fast journeys between train stations or across rivers and lakes. They are envisaged to operate around-the-clock. Droneports (also called Vertiports or Skyports) will develop at various points in the city, allowing easy access, transfer to other modes of transportation, and technical support such as battery charging and maintenance for air taxis. This, together with existing no-fly zones due to safety restrictions, will lead to the development of certain routes above the city. A typical approach for aviation administrations is to bundle such routes in corridors to keep drone traffic separated from other airspace users (for a recent example see [2]). Working or living under or near such corridor will overly expose citizens to air taxi noise emissions and could become a limiting factor for urban air mobility. This discussion paper argues that citizens have to be viewed as stakeholders in urban air transportation, regardless of whether they intend to use it or not, and that a concept of resident PNS will be beneficial to UAM. Web-based services and smartphones allow the current state of information to be easily accessed and updated, thus enabling them to be used to foster urban air mobility.

\section{Noise Concerns}

Organizing UAM in a manner that is similar to today's commercial air traffic, i.e. using certain corridors (or tubes, see [3]), is meant to guarantee safe operations and keep different kinds of air traffic apart from each other. However, in doing so the noise problem will not only exist in the vicinity of droneports, where vehicles take off and land, but also for citizens living or working below these corridors, which are projected to be at an altitude between 500 and 1500 feet. "One potential outcome of scaled-up drone operations is an increase in urban noise volume exceedances above legal or desired limits" [4]. An expected decrease in quality of life and/or real estate values due to urban air mobility can lead to lawsuits and/or restrictions. Strong public opposition could finally become a show-stopper for urban air mobility, at least in western megacities, which is also the reason why the aviation industry sees "involving community engagement now vitally important" [5].

Among all sources of environmental noise, research has shown that the noise generated from aviation is the most annoying [6]. Own research has shown that, among all concerns, those relating to noise are the strongest predictor of acceptance of civil drones: people who are concerned about noise show least acceptance. Furthermore the usage of air taxis finds only little acceptance among the public. In a representative study in 
Germany, $85 \%$ of the respondents in a telephone survey indicated they would not use air taxis [7]. Even among those who would consider using UAM, their acceptance is likely to vanish when air taxis are flying above their house or workplace.

Annoyance can be seen as a multidimensional construct comprising three elements: firstly the experience of repeated noise-related disturbance as well as the behavioral response to cope with it, secondly the emotional/attitudinal response to the sound and its disturbing impact, and lastly the perceived lack of capacity to cope with the noise [8]. The coping style can be either problem-oriented or emotion-oriented, whereas the problem-oriented coping is more proactive and the latter more reactive in nature.

Communities can differ in their tolerance to noise. The community noise tolerance level (CTL) is described as the noise level at which half of the population reports being "highly annoyed" and is measured using a standard set of questions. Research has found that the same objective noise level measured in $\mathrm{dB}$ can lead to different CTLs at different locations. In addition to personal, situational, and cultural influences, the rate of abrupt change in noise levels during recent years has been identified as factor that influences the community noise level, with airports that have a high rate of change leading to higher annoyance levels than airports with a low rate of change [9].

Most of the findings on aviation noise relate to classic air traffic, to jet aircraft, and airports, so they have to be downscaled when applied to UAM. The industry seems confident in the potential to produce low-noise vehicles [1]. However, with 24/7 operation envisaged, with predicted airspeeds exceeding 100 $\mathrm{mph}$, and with the basic physical fact that when air meets a structure it produces sound (true for propellers as well for the cabin), the noise problem will be persistent with UAM. Not only that UAM noise will be an additional factor to other environmental noise sources such as road, rail, aviation, and industry; It will "come on top" for all citizens living or working on higher floors in the tall buildings of our urban canyons.

\section{Participatory noise sensing}

Noise mapping using smartphones allows citizens to actively engage and contribute data of personal relevance [10]. Real-time measurements with mobile applications represent the individual's perception of noise. Using individual smartphones for sensing might face calibration issues, however, every new generation of devices outperforms its predecessors. Noise mapping using smartphones has made large advances in recent years. Applications available today enable residents to submit noise data and to provide additional information directly from their smartphone [11]. When proposing a concept of citizen PNS, Guillaume and colleagues [12] list more than ten different smartphone tools for noise mapping. An in-depth description of "NoiseCapture," an open-science crowdsourcing application for producing community noise maps is provided by Picaut et al. [13]. NoiseCapture [14] is a smartphone application that is freely available and was developed in the framework of a research network partially funded by the European Community. The application is dedicated to the android platform and has been in use since August 2017. Using such a tool, residents can contribute to noise mapping with data specifically relevant to them while still maintaining user anonymity.

\section{Proposed urban air mobility management}

An urban air traffic management (ATM) system is installed at the city level for public governance and tracks all flights in urban airspace. For noise monitoring, the system calculates flight noise-profiles either by using emission characteristics from a repository of all air-taxi models and combining it with relevant data on current weather conditions (e.g. wind, cloud base, humidity) or by using real-time measurements provided by stationary devices or mobile applications. Onsite measurements are superior to other methods as they are closest to the true noise perceived by the citizen. Artificially calculated measures can never include all relevant data and are likely to underestimate the true noise values. Measurement data from unsupervised stations or data harvested by volunteers will undergo sound spectrum analysis to be checked for outliers and faithfulness before being included in the database. Combining UAM traffic data with incoming noise measurement files using timestamps and/or geopositioning data will allow UAM noise to be distinguished from other environmental noise sources when necessary.

Noise profiles will be generated and analyzed under public control. The data will be stored geographically like footprints or "noise tracks" on regional maps. Track colors represent noise intensity at ground level, with track density showing the frequency of flights at a given location. This map is constantly updated at weekly intervals and provides the ongoing base for the calculation of noise impact. It is accessible for the public.

Whenever possible, the urban air traffic management system is able to adjust requested flight patterns so that the noiseburden is shared in an objective and transparent manner. For instance within a dynamic skylane network, altitudes could be adjusted or the lateral route of flight can be adapted based on prior noise load at a given location.

\section{Conclusions}

Air mobility will come to our cities within the next decades. It will come as an additional platform in urban mobility and it will be an additional source of environmental noise for citizens. It will receive extra public attention because it will be used only by few people, but it will produce elevated noise volumes for many. One way to support the successful introduction of UAM is to invite residents to actively participate in noise sensing by using smartphone applications. Such application should be available at no cost for the user and for all platforms. It could be even more successful if additional smart city functions were offered, such as linking with other transport systems, public services, or an option to request a temporary flight ban over a certain location, e.g. when there is a neighborhood festivity.

Making reference to individual noise loads, as proposed in this concept, would support the onset of UAM while safeguarding the wellbeing of citizens. The less noisy urban air 
taxi operation turns out to be for the residents, the more successful its introduction can be - at little extra cost.

\section{REFERENCES}

[1] Uber 2016. Fast-forwarding to a future of on-demand urban air transportation. Uber Elevate.

[2] Ministry of Civil Aviation of the Government of India (2019). Drone ecosystem policy roadmap.

[3] Balakrishnan, K., Polastre, J., Mooberry, J., Golding, R. \& Sachs, P. (2018). Blueprint for the sky. The roadmap for the safe integration of autonomous aircraft. Airbus A3.

[4] International Transport Forum (OECD) (2018). (Un)certain Skies? Drones in the World of Tomorrow. Retrieved from https://www.itf-oecd.org/uncertainskies-drones [29 Aug 2018]

[5] Civil Air Navigation Services Organisation (2015). Managing the impacts of aviation noise. A guide for airport operators and air navigation service providers. CANSO.

[6] Guski, R., Schreckenberg, D. \& Schuemer, R. (2017). WHO Environmental Noise Guidelines for the European Region: A Systematic Review on Environmental Noise and Annoyance. International Journal of Environmental Research and Public Health 14(12):1539. DOI: 10.3390/ijerph14121539.

[7] Eißfeldt, H., Vogelpohl, V., Stolz, M., Papenfuß, A., Biella, M., Belz, J. \& Kügler D. (2018) The acceptance of civil drones in Germany. Manuscript submitted for publication.

[8] Schreckenberg, D., Belke, C. \& Spilski, J. (2018). The Development of a Multiple-Item Annoyance Scale (MIAS) for transportation noise annoyance. Int.J. Environ. Res. Public Health 2018, 15, 971.

[9] Gelderblom , F. B., Gjestland, T., Fidell, S. \& Berry, B.(2017). On the stability of community tolerance for aircraft noise. AAA Vol.103, 17-27.

[10] Maisonneuve, N., Stevens, M. \& Ochab, B. (2010). Participatory noise pollution monitoring using mobile phones. Information polity, 15, 51-71.

[11] Becker, M., Caminiti, S., Fiorella, D., Francis, L. Gravino, P. et al. (2013). Awareness and learning in participatory noise sensing. PloS ONE 8(12) e81638. DOI: 10.1371/journal.pone.0081638.

[12] Guillaume, G., Can, A, Petit, G., Fortin, N., Palominos, S., Gauvreau, B. Bocher, E. \& Picaut, J. (2016). Noise mapping based on participative measurements. Noise Mapping, 2016; 3:140-156

[13] Picaut, J., Fortin, N., Bocher, E., Petit, G., Aumond, P. \& Guillaume, G. (2019) An open-science crowdsourcing approach for producing community noise maps using smartphones. Building and Environment. Vol. 148, pp. 20-33.

[14] https://www.ifsttar.fr/en/online-resources/science-and-society/spatial-

planning/focus-on/an-application-to-evaluate-our-sound-environmentnoisecapture/ Accessed on 12 Jan 2019. 